\title{
Flora vascular não-arbórea de uma floresta de grota na Serra da Mantiqueira, Zona da Mata de Minas Gerais, Brasil
}

\author{
Luiz Menini Neto ${ }^{1,2,8}$, Carolina Nazareth Matozinhos ${ }^{3}$, Narjara Lopes de Abreu ${ }^{4}$, \\ Arthur Sérgio Mouço Valente ${ }^{5,6}$, Kelly Antunes ${ }^{5}$, Filipe Soares de Souza ${ }^{5}$, \\ Pedro Lage Viana ${ }^{7}$ \& Fátima Regina Gonçalves Salimena ${ }^{5}$ \\ ${ }^{1}$ Centro de Ensino Superior de Juiz de Fora - CES, \\ Rua Luz Interior, Santa Luzia, CEP 36030-776, Juiz de Fora, MG, Brasil \\ ${ }^{2}$ Programa de Pós-graduação em Diversidade Vegetal, \\ Escola Nacional de Botânica Tropical - ENBT, \\ Instituto de Pesquisas Jardim Botânico do Rio de Janeiro, Rio de Janeiro, RJ, Brasil \\ ${ }^{3}$ Programa de Pós-graduação em Ciências Biológicas (Botânica), Museu Nacional, \\ Universidade Federal do Rio de Janeiro - UFRJ, Rio de Janeiro, RJ, Brasil \\ ${ }^{4}$ Programa de Pós-graduação em Ecologia, \\ Universidade Federal de Juiz de Fora - UFJF \\ Juiz de Fora, MG, Brasil \\ ${ }_{5}^{5}$ Departamento de Botânica, Universidade Federal de Juiz de Fora - UFJF \\ Campus Universitário, Martelos, CEP 36036-900, Juiz de Fora, MG, Brasil \\ ${ }^{6}$ Programa de Pós-graduação em Engenharia Florestal, \\ Universidade Federal de Lavras - UFLA Lavras, MG, Brasil \\ ${ }^{7}$ Programa de Pós-graduação em Biologia Vegetal, \\ Universidade Federal de Minas Gerais - UFMG, Belo Horizonte, MG, Brasil \\ ${ }^{8}$ Autor para correspondência: Luiz Menini Neto,e-mail: menini_neto@hotmail.com
}

MENINI NETO, L., MATOZINHOS, C.N., ABREU, N.L., VALENTE, A.S.M, ANTUNES, K., SOUZA, F.S., VIANA, P.L. \& SALIMENA, F.R.G. Non-arboreal vascular flora of a ravine forest in the Mantiqueira Range, Zona da Mata of Minas Gerais, Brazil. Biota Neotrop., 9(4): http://www.biotaneotropica.org.br/v9n4/en/abst ract?inventory+bn01009042009.

\begin{abstract}
Serra Negra is an important remnant of Atlantic Forest located in the southern part of the Zona da Mata of Minas Gerais, in Mantiqueira Range, composed by a mosaic of "campos rupestres" (on quartzite outcrops), cloud scrubs, lower-montane to upper montane seasonal semi-deciduous forests or evergreen cloud forests, and riparian to interfluvial forests. Despite floristic importance of this area, there are only two Natural Patrimony Private Reserves: São Lourenço do Funil and Serra Negra. The study area is a ravine forest fragment (evergreen forest), comprising $c a$. 0.9 ha, localized in the Cânion do Ribeirão do Funil, in Funil Village, municipality of Rio Preto, southern of Serra Negra. The present study was carried out from 2004 to 2009 and its goals were: (1) to survey the non-arboreal vascular flora of the area, (2) discuss plant habits and habitats, and (3) describe the physiognomy of this forest fragment. A total of 157 taxa of vascular plants (41 ferns and 116 angiosperms) were recorded, belonging to 48 families (10 of ferns and 38 of angiosperms). The richest families of ferns and angiosperms were Pteridaceae (11 spp.) and Orchidaceae (27 spp.), respectively. The most representative habit was herbaceous (124 spp.), within which epiphyte species (42 spp.) must be emphasized, representing about $25 \%$ of all recorded species. Twelve species are cited in the endangered species list of Minas Gerais State (two ferns and 10 angiosperms). The high number of species found in this small area remarks the importance of this fragment for the knowledge of biodiversity of Serra Negra, in particular, and Minas Gerais, in general. In addition, the results reinforce the need of an action plan addressed to the conservation of the region.

Keywords: Serra Negra, atlantic forest, campo rupestre, floristics, herbs, shrubs, lianas, epiphytes.
\end{abstract}

MENINI NETO, L., MATOZINHOS, C.N., ABREU, N.L., VALENTE, A.S.M, ANTUNES, K., SOUZA, F.S., VIANA, P.L. \& SALIMENA, F.R.G. Flora vascular não-arbórea de uma floresta de grota na Serra da Mantiqueira, Zona da Mata de Minas Gerais, Brasil. Biota Neotrop., 9(4): http://www.biotaneotropica.org. br/v9n4/pt/abstract?inventory+bn01009042009.

Resumo: A região da Serra Negra constitui um importante remanescente de floresta atlântica situado no sul da Zona da Mata mineira, na Serra da Mantiqueira, composta por um mosaico de campos rupestres (nos afloramentos de quartzito) a arbustais nebulares, florestas estacionais semideciduifólias a perenifólias e florestas nebulares, de ambientes inferomontanos a superomontanos ripícolas a interfluviais. A área de estudo é um fragmento de 
floresta de grota (floresta perenifólia ripícola), de aproximadamente 0,9 ha, situada no Cânion do Ribeirão do Funil, na Vila do Funil, município de Rio Preto, localizada no sul da Serra Negra. O presente trabalho foi realizado entre os anos de 2004 e 2009 e teve como objetivos o conhecimento da flora vascular não-arbórea, a discussão dos hábitos e habitats das plantas e a descrição da fisionomia do fragmento. Foram registrados 157 táxons de plantas vasculares (sendo 41 pteridófitas e 116 angiospermas), pertencentes a 48 famílias (10 de pteridófitas e 38 de angiospermas). As famílias de maior riqueza específica foram Orchidaceae, dentre as angiospermas, com 27 espécies e Pteridaceae, dentre as pteridófitas, apresentando 11 espécies. O hábito mais representativo foi o herbáceo (124 spp.), destacando-se as espécies epífitas (42 spp.), que perfazem cerca de $25 \%$ de todas as espécies registradas na área. Doze espécies estão incluídas na lista de espécies ameaçadas de extinção no estado de Minas Gerais (duas pteridófitas e 10 angiospermas). O elevado número de espécies encontradas em uma área consideravelmente pequena ressalta a importância deste fragmento para a diversidade da Serra Negra e aponta para a necessidade de implantação de um plano de ação para sua conservação.

Palavras-chave: Serra Negra, floresta atlântica, campo rupestre, florística, ervas, arbustos, lianas, epífitas.

\section{Introdução}

A floresta atlântica está distribuída por três países da América do Sul (Brasil, Paraguai e Argentina) (Câmara 2005) e é considerada um dos hotspots mundiais de biodiversidade, em virtude do elevado número de espécies animais e vegetais que ocorrem em seus domínios, sobretudo endêmicas, e a rápida redução de extensão que vem sofrendo ao longo dos anos (Myers et al. 2000), restando atualmente apenas $7-8 \%$ de área florestada original, de modo que figura entre os ecossistemas mais devastados e ameaçados da Terra (Morellato \& Haddad 2000, Galindo-Leal \& Câmara 2005). A delimitação de seu domínio foi por muitos anos motivo de controvérsia, mas Oliveira-Filho \& Fontes (2000) auxiliaram na definição mais precisa de sua área, ao demonstrarem que não apenas as formações costeiras de Floresta Ombrófila Densa e ecossistemas associados fazem parte da floresta atlântica, mas também as florestas estacionais interioranas deveriam integrar um dos mais diversos biomas do mundo.

O estado de Minas Gerais manteve sua cobertura florestal original pouco alterada até o início do século XIX, quando sofreu o primeiro grande impacto de sua paisagem natural com a introdução da cultura do café. Originalmente representava um contínuo vegetacional com a floresta do médio Paraíba, ao sul, e a do vale do rio Doce, ao norte; a oeste com os campos naturais do centro e sul de Minas (Valverde 1958). Somente as áreas de difícil acesso resguardaram remanescentes de vegetação, representados atualmente pelas florestas montanas ou altomontanas, campos de altitude e campos rupestres.

A Serra Negra representa um destes remanescentes, formada por um complexo de serras que corre desde Bom Jardim de Minas, a oeste, até Santa Bárbara do Monte Verde, a leste. Localizada na Serra da Mantiqueira, forma o corredor sudeste e integra a área de Bom Jardim de Minas, definida como prioritária para conservação biológica no estado por Costa et al. (1998) e atualmente com indicações para implantação de unidades de conservação (Drummond et al. 2005).

Na Serra encontram-se a Reserva Particular do Patrimônio Natural (RPPN) São Lourenço do Funil, no município de Rio Preto e a RPPN Serra Negra, no município de Lima Duarte, em processo de criação. Distante cerca de $25 \mathrm{~km}$ da Serra do Ibitipoca, com altitudes e fitofisionomia semelhantes, apresenta numerosas nascentes e cursos d'água, constituindo um corredor florístico no sentido leste-oeste, entre a Mantiqueira Setentrional, Vale do Paraíba do Sul e Mantiqueira Meridional e no sentido norte-sul entre Ibitipoca e o Maciço do Itatiaia (Valente 2007).

Nesta região destacam-se as florestas de grota ou cânions, fragmentos de floresta perenifólia ripícola localizados próximos à calha dos ribeirões que drenam a região e que acumulam materiais decompostos de áreas mais elevadas e deposições laterais. Há grande disponibilidade de água e matéria orgânica, que aliados à profundidade e maior umidade dos solos propiciam o desenvolvimento de uma vegetação mais adensada. As grotas têm importância especial pelas formações espeleológicas e pelo endemismo potencial (Dias et al. 2002).

O Cânion do Ribeirão do Funil é um destes ambientes ímpares na região, com alta beleza cênica e grande fluxo de visitação pública, sobretudo em períodos de festas populares e feriados prolongados. Devido à sua vulnerabilidade e fragilidade, a presença desordenada de turistas altera completamente a dinâmica de decomposição e ciclagem de matéria orgânica nos solos.

Em muitas regiões do estado de Minas Gerais, a inexistência de inventários biológicos ou a existência apenas de estudos incipientes impossibilitam a avaliação das áreas e indicação de ações concretas para conservação da sua biodiversidade. A maioria dos estudos florísticos realizados em ambientes florestais no estado prioriza o estrato arbóreo (p. ex. van den Berg \& Oliveira-Filho 2000, Lopes et al. 2002, Marangon et al. 2003, Rodrigues et al. 2003, Silva et al. 2003, Dalanesi et al. 2004, França \& Stehmann 2004, Silva et al. 2004, Valente 2007), com raras exceções que abrangem também as plantas não-arbóreas (Araújo et al. 2002, Lombardi et al. 2005, Pifano et al. 2007), enquanto os estudos em áreas com predomínio dos campos rupestres englobam maior espectro de formas de vida (Giulietti et al. 1987, Perón 1989, Pedralli et al. 1997, Pirani et al. 2003, Viana \& Lombardi 2007, Alves \& Kolbek 2009).

Em contrapartida, estudos que abrangem apenas as formas nãoarbóreas em formações florestais são escassos, tanto no estado de Minas Gerais (Andrade 1992, Meira-Neto \& Martins 2000), quanto em outros estados brasileiros (Diesel \& Siqueira 1991, Bernacci 1992, Muller 1999, Kozera \& Rodrigues 2005, Groppo \& Pirani 2005, Kozera et al. 2009), sendo mais comuns os estudos exclusivos da flora epifítica (Waechter 1986, Dislich \& Mantovani 1998, Borgo et al. 2002, Borgo \& Silva 2003, Rogalski \& Zanin 2003, Giongo \& Waechter 2004, Hefler \& Faustioni 2004, Gaiotto \& Acra 2005, Menini Neto et al. 2009).

Deve ser ressaltado que trabalhos enfocando todas as formas de vida e todos os grupos de plantas vasculares não-arbóreas em formações florestais no domínio atlântico são inexistentes, de modo que o presente estudo vem preencher uma importante lacuna no conhecimento florístico deste bioma, tendo em vista que as florestas 
ombrófilas tropicais são as áreas mais ricas em espécies vegetais do planeta, com destaque para as plantas não-arbóreas, sobretudo as de hábito epífitico (Gentry \& Dodson 1987a).

Desse modo, os objetivos deste estudo foram conhecer a composição florística das espécies vasculares não-arbóreas do Cânion do Ribeirão do Funil, descrever a fisionomia do fragmento e discutir o hábito e habitat das espécies, como subsídio para planos de conservação deste tipo de ambiente na Serra Negra.

\section{Material e Métodos}

A Serra Negra é um componente do Complexo da Mantiqueira, no sul da Zona da Mata mineira, ocupando parte dos municípios de Lima Duarte, Santa Bárbara do Monte Verde, Rio Preto e Olaria (Figura 1). A vegetação natural da Serra insere-se no domínio atlântico, formada por um mosaico de campos rupestres (nos afloramentos de quartzito) a arbustais nebulares, florestas estacionais semideciduifólias a perenifólias e florestas nebulares, de ambientes inferomontanos a superomontanos ripícolas a interfluviais. Apresenta altitude entre 900-1700 m e clima do tipo Cwb (Köppen) com média da precipitação anual de $1.886 \mathrm{~mm}$ (EMATER 2003).

O estudo é parte do inventário florístico da Serra Negra e foi reali-

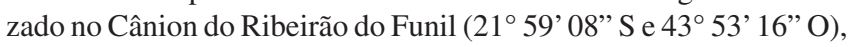
município de Rio Preto, em um fragmento de floresta de grota (floresta perenifólia ripícola), orientado no sentido norte-sul, situado a aproximadamente 900 m.s.n.m. e com uma área de cerca de 0,9 ha (Figura 2). De acordo com Dias et al. (2002) as grotas são controladas estruturalmente pelas falhas e diáclases das rochas, onde as águas de percolação abrem lentamente profundas incisões. Esse processo, no Ribeirão do Funil, levou à formação da foz em um sumidouro por vale íngreme e estreito entre dois serrotes de rochas quartzíticas (Figura 3). Após uma área aluvial o ribeirão corre por uma exten- são de $200 \mathrm{~m}$ em vale estreito até o sumidouro, por onde a água é percolada para o subsolo, aflorando cerca de $100 \mathrm{~m}$ a jusante, em cachoeira, ligando-se ao Ribeirão Sant'Ana. Por ser muito íngreme, a maior parte da vegetação do vale tem apenas influência indireta do Ribeirão. Uma pequena parte é influenciada diretamente pela inundação periódica que ocorre em períodos chuvosos com duração de semanas, apresentando variação de extensão na área inundada de acordo com o entupimento do sumidouro.

A fitofisionomia do Cânion do Ribeirão do Funil foi definida com base no sistema de classificação proposto por Oliveira-Filho (2009), apresentando características de Floresta Latifoliada Estacional Perenifólia Tropical Inferomontana Ripícola. Esta fitofisionomia, equivaleria à classificação Floresta Ombrófila Densa Aluvial do Instituto Brasileiro de Geografia e Estatística (IBGE) (Veloso et al. 1991) por se tratar de formação ribeirinha, no entanto, difere por não ocupar terraços aluvionares, mas os vales encaixados com diques rochosos. A alta umidade local, favorecida pelo córrego perene e fundo de vale justificam o predomínio de árvores com folhagem "sempre-verde", embora o clima local seja marcadamente estacional. Sua ocorrência é comum no fundo de vales no Domínio Atlântico, onde a estação seca é compensada por reservas de água no solo e as margens úmidas a saturadas de riachos e lagos, não são sujeitas a inundações periódicas (ripícolas).

O estrato arbóreo é composto por um número relativamente pequeno de espécies (observações pessoais), apresentando dossel de cerca de $10 \mathrm{~m}$, destacando-se no interior da floresta Bathysa cuspidata (St. Hil.) Hook. f. (Rubiaceae), Cabralea canjerana (Vell.) Mart. (Meliaceae), Cybianthus cuneifolius Mart. (Myrsinaceae), Mollinedia glabra (Spreng.) Perkins e M. schottiana (Spreng.) Perkins (Monimiaceae), Nectandra oppositifolia Nees \& Mart. ex Nees (Lauraceae), Picramnia glazioviana Engl. (Picramniaceae) e Podocarpus sellowii Klotzsch ex Endl. (Podocarpaceae). A área

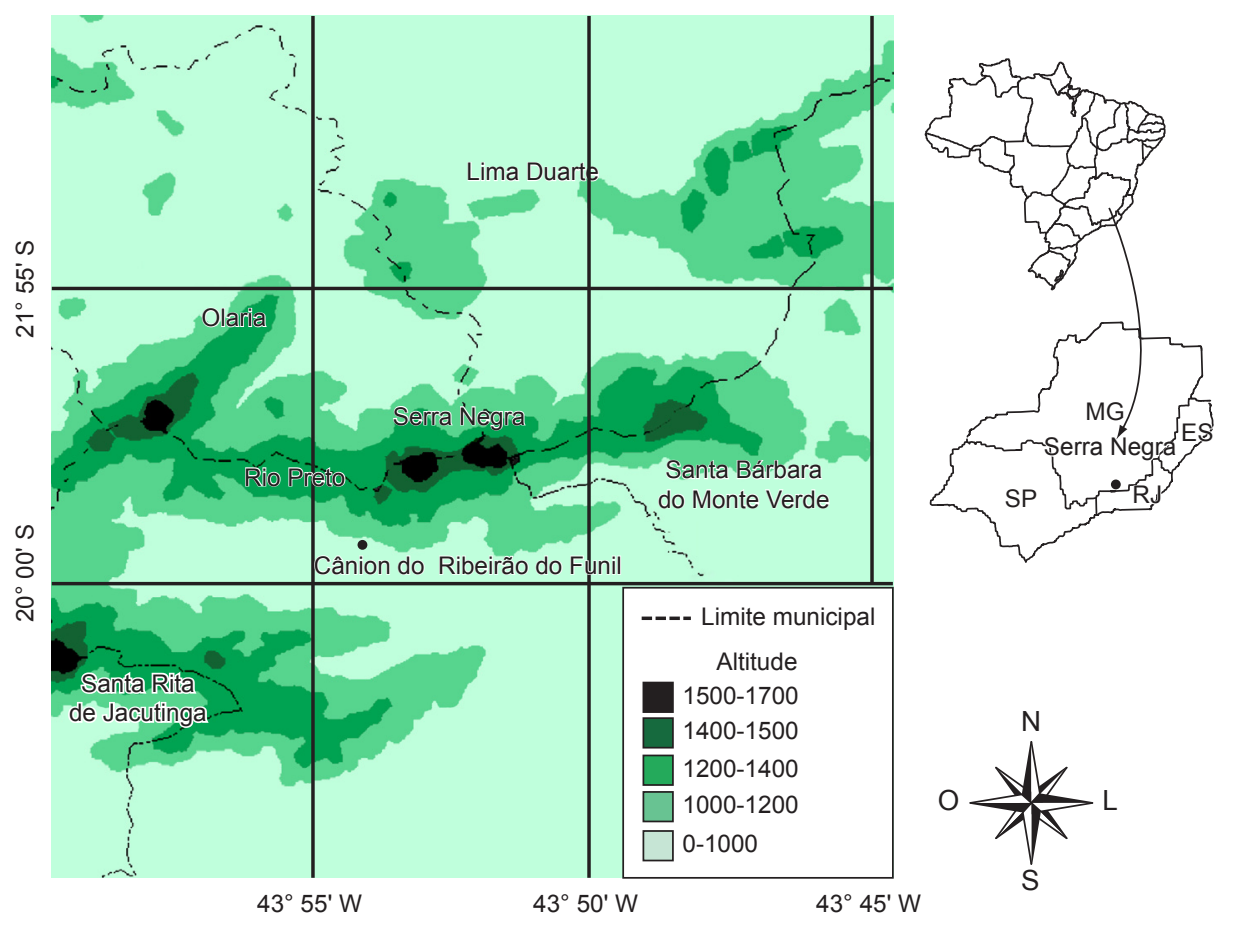

Figura 1. Localização da área de estudo.

Figure 1. Location of the study area. 


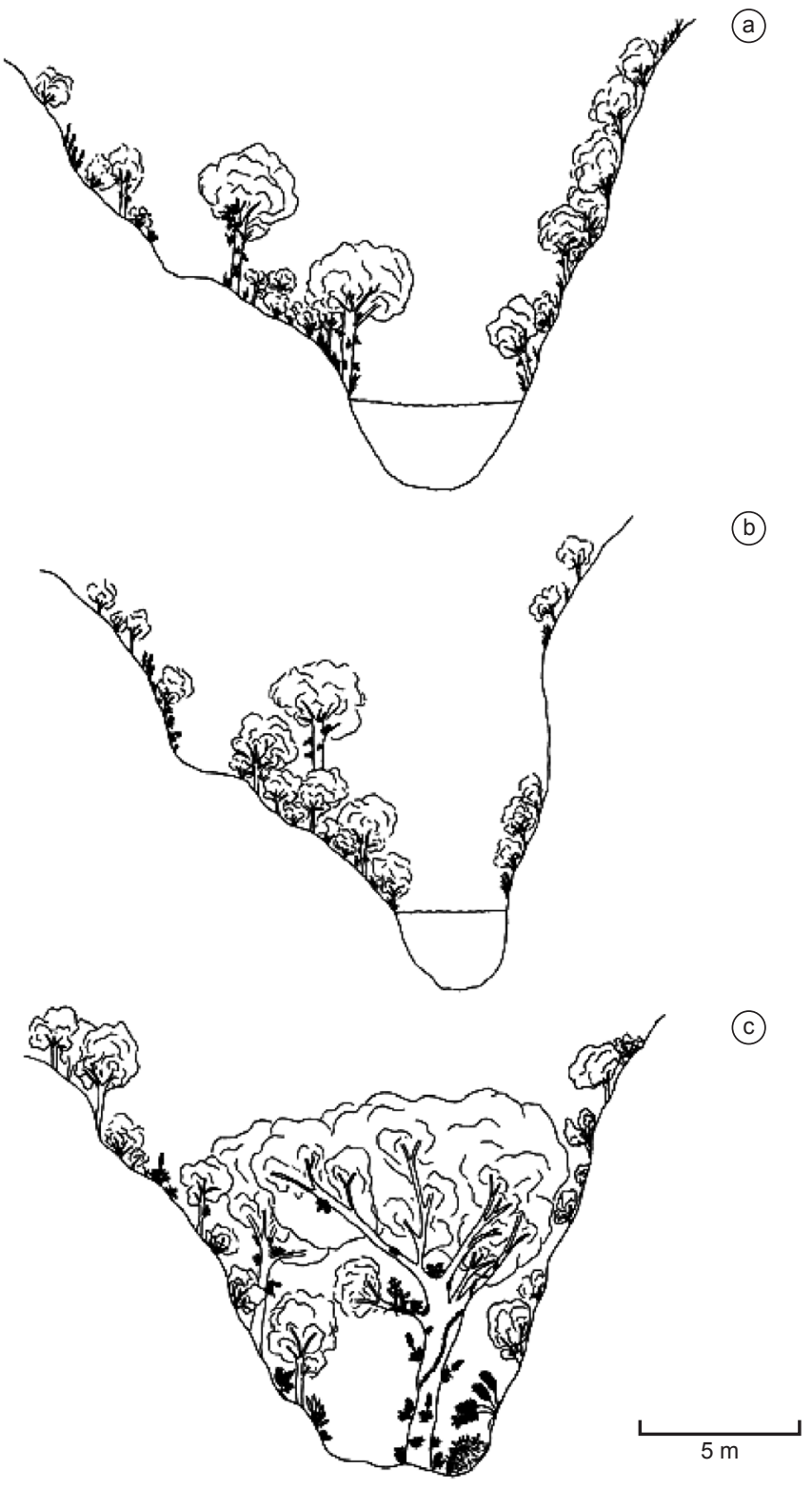

Figura 2 . Perfil de três seções do Cânion do Ribeirão do Funil. A. região próxima ao início do Cânion; B. região próxima ao "sumidouro" do Ribeirão do Funil; C. interior do Cânion.

Figure 2. Profile of three sections of the Cânion do Ribeirão do Funil. A. region near beginning of the Cânion; B. region near "sumidouro" of the Ribeirão do Funil; C. interior of the Cânion.

de transição da floresta de grota com o campo rupestre é composta por Aspidosperma olivaceum Müll. Arg. (Apocynaceae), Clusia criuva Cambess. (Clusiaceae), Eremanthus erythropappus (DC.) MacLeish e E. glomerulatus Less. (Asteraceae), Eugenia involucrata DC. (Myrtaceae), Inga blanchetiana Benth. (Fabaceae), Schefflera vinosa (Cham. \& Schltdl.) Frodin \& Fiaschi, Solanum decorum Sendtn. (Solanaceae) e Ternstroemia brasiliensis Cambess. (Ternstroemiaceae).

Foram realizadas expedições mensais de coleta entre os anos de 2004 e 2009. A amostragem foi realizada através de caminhamento (Filgueiras et al. 1994) por trilha existente na área de estudo, por meio de coleta e fotografia de espécimes, que foram incorporados ao herbário CESJ, da Universidade Federal de Juiz de Fora (acrônimo de
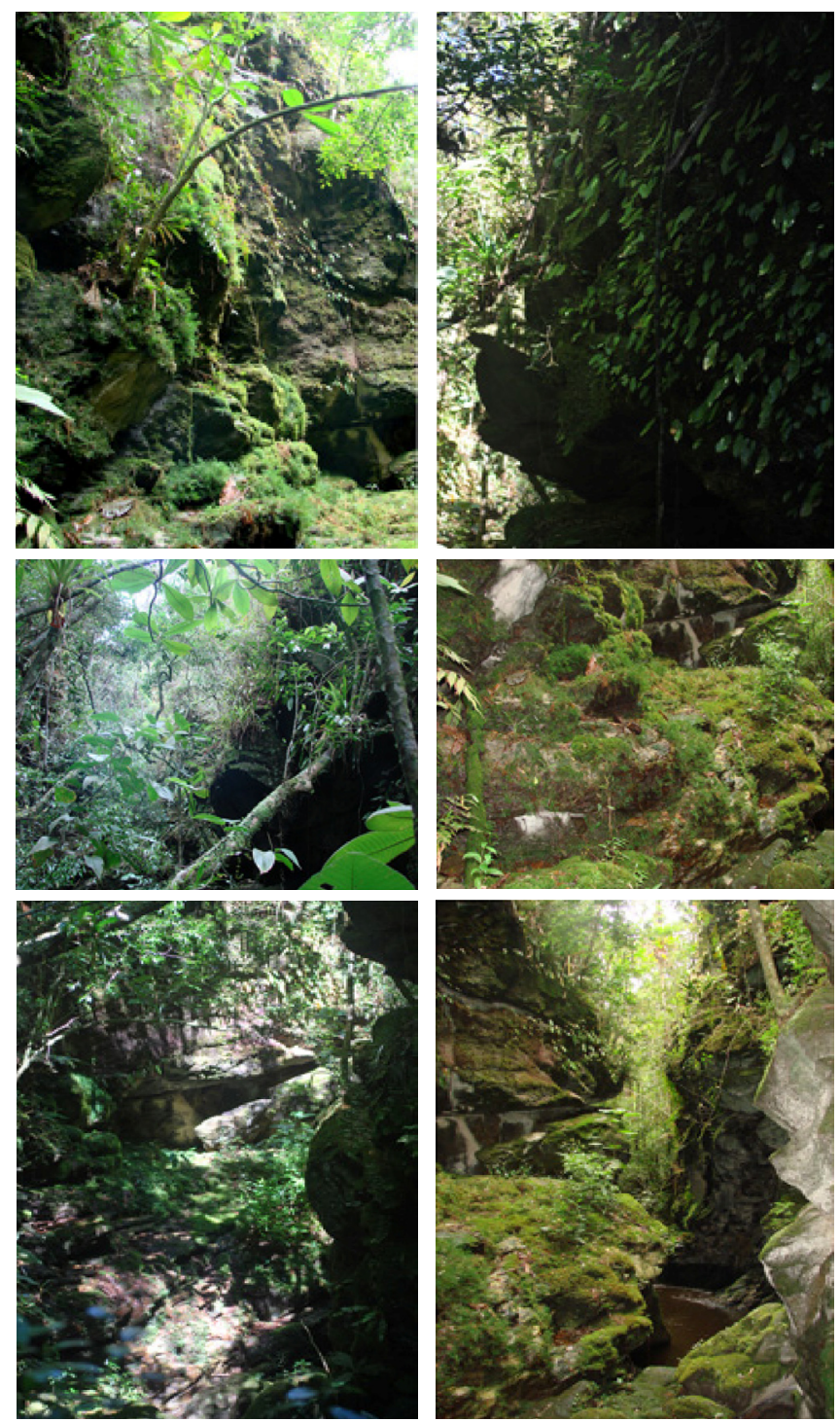

Figura 3. Cânion do Ribeirão do Funil.

Figure 3. Cânion do Ribeirão do Funil.

acordo com Holmgren \& Holmgren 1998.). A metodologia de coleta seguiu os padrões propostos por Mori et al. (1990), na qual os dados relevantes para cada espécime coletado, como hábito e ambiente de ocorrência, foram anotados em campo. Os espécimes coletados foram identificados por especialistas (conforme Tabela 1) ou por comparação com o acervo do herbário CESJ. Os nomes de espécies e autores foram conferidos através de consulta ao International Plants Names Index (www.ipni.org). As famílias de monilófitas estão de acordo com Smith et al. (2006), as de Lycophyta seguem Tryon \& Tryon (1982) e as de angiospermas segundo APG II (2003). A terminologia empregada para os hábitos das plantas está de acordo com Mori et al. (1990), exceto para o termo hemiepífita, utilizado segundo Benzing (1990).

\section{Resultados}

No levantamento da flora vascular não-arbórea do Cânion do Ribeirão do Funil foram amostrados 157 táxons pertencentes a 48 famílias (Tabela 1), ocorrendo principalmente no interior da flo- 
Flora de uma floresta de grota na Serra da Mantiqueira

Tabela 1. Famílias e espécies de plantas vasculares não-arbóreas registradas na floresta do Cânion do Ribeirão do Funil, Rio Preto - MG.

Table 1. Families and species of non-arboreal vascular plants recorded in Cânion do Ribeirão do Funil forest, Rio Preto - MG.

\begin{tabular}{|c|c|c|c|}
\hline Famílias/Espécies & Habitat & Hábito & CESJ \\
\hline \multicolumn{4}{|c|}{ Lycophyta } \\
\hline \multicolumn{4}{|l|}{ SELAGINELLACEAE (F.S.Souza, A.Salino) } \\
\hline Selaginella decomposita Spring & $\mathrm{Fl}$ & ER & 46532 \\
\hline S. tenuissima Fée & $\mathrm{Fl}$ & ER & 50206 \\
\hline \multicolumn{4}{|c|}{ Monilófitas } \\
\hline \multicolumn{4}{|l|}{ ANEMIACEAE (F. S. Souza, A. Salino) } \\
\hline Anemia raddiana Link & $\operatorname{Tr}$ & $\mathrm{ET}$ & 46554 \\
\hline Anemia sp. & $\operatorname{Tr}$ & $\mathrm{ER} / \mathrm{ET}$ & 46552 \\
\hline \multicolumn{4}{|l|}{ ASPLENIACEAE (F. S. Souza, A. Salino) } \\
\hline Asplenium auriculatum $\mathrm{Sw}$. & $\operatorname{Tr}$ & $\mathrm{ET} / \mathrm{ER}$ & \\
\hline A. claussenii Hieron. & $\mathrm{Cr} / \mathrm{Fl}$ & ET/ER & 42266 \\
\hline A. martianum C. Chr. & $\mathrm{Fl}$ & ET & 42313 \\
\hline A. oligophyllum Kaulf. & $\mathrm{Fl}$ & ET & 46534 \\
\hline A. radicans L. var. cirrhatum (Rich ex Willd.) Rosenst. & $\mathrm{Fl}$ & ET & 46564 \\
\hline A. radicans L. var. partitum (Klotzsch) Hieron. & $\mathrm{Fl}$ & ET & 43877 \\
\hline A. salicifolium $\mathrm{L}$. & $\mathrm{Fl}$ & Esax & 48549 \\
\hline \multicolumn{4}{|l|}{ BLECHNACEAE (F. S. Souza, A. Salino) } \\
\hline Blechnum gracile Kaulf. & $\mathrm{Fl}$ & ET & 42269 \\
\hline \multicolumn{4}{|l|}{ DRYOPTERIDACEAE (L. C. N. Melo) } \\
\hline Elaphoglossum decoratum (Kunze) T. Moore & $\operatorname{Tr}$ & ER & 46555 \\
\hline E. glabellum J. Sm. & $\mathrm{Fl}$ & ER & 46565 \\
\hline E. glaziovii (Fée) Brade & $\mathrm{Fl}$ & ER/Esax & 42268 \\
\hline Olfersia cervina (L.) Kunze & $\mathrm{Fl}$ & ER/Esax & 46558 \\
\hline \multicolumn{4}{|l|}{ HYMENOPHYLLACEAE (F. S. Souza, A. Salino) } \\
\hline Hymenophyllum elegans Spreng. & $\mathrm{Fl}$ & ER & 46533 \\
\hline Trichomanes hymenophylliodes Bosch & $\mathrm{Fl}$ & ER & 46556 \\
\hline T. pilosum Raddi & $\mathrm{Fl}$ & ET & 46561 \\
\hline \multicolumn{4}{|l|}{ OLEANDRACEAE (F. S. Souza, A. Salino) } \\
\hline Oleandra hirta Brack. & $\mathrm{Fl}$ & ET/ER & 42264 \\
\hline \multicolumn{4}{|l|}{ POLYPODIACEAE (F. S. Souza, A. Salino) } \\
\hline Campyloneurum acrocarpon Fée & $\operatorname{Tr}$ & ER & 46557 \\
\hline C. nitidum (Kaulf.) C. Presl & $\mathrm{Fl}$ & Eep & 46559 \\
\hline Microgramma percussa (Cav.) de la Sota & $\mathrm{Fl}$ & Eep/ER & 46539 \\
\hline M. tecta (Kaulf.) Alston & $\mathrm{Fl}$ & Eep/ER & 42241 \\
\hline Pecluma chnoophora (Kunze) Salino \& F. Costa Assis & $\mathrm{Fl}$ & $\mathrm{ER} / \mathrm{ESax}$ & 46551 \\
\hline P. recurvata (Kaulf.) M.G. Price & $\mathrm{Fl}$ & ET & 46545 \\
\hline Serpocaulon catharinae (Langsd. \& Fisch.) A.R.Sm. & $\mathrm{Fl}$ & Eep & 47087 \\
\hline S. fraxinifolium (Jacq.) A.R.Sm. & $\mathrm{Fl}$ & Hem & 46549 \\
\hline S. meniscifolium (Langsd. \& Fisch.) A.R.Sm. & $\mathrm{Fl}$ & $\mathrm{ET}$ & 42265 \\
\hline \multicolumn{4}{|l|}{ PTERIDACEAE (F. S. Souza, A. Salino) } \\
\hline Adiantopsis radiata $(\mathrm{L}$.) Fée & $\mathrm{Fl}$ & ET & 42311 \\
\hline Doryopteris collina (Raddi) J. Sm. & $\operatorname{Tr}$ & ER & 46546 \\
\hline D. ornithopus (Mett.) J. Sm. & $\operatorname{Tr}$ & ET & 42243 \\
\hline D. sagittifolia (Raddi) J. Sm. & $\mathrm{Fl}$ & ET & 42267 \\
\hline Eriosorus biardii (Fée) A.F.Tryon & $\mathrm{Fl}$ & ET & 47086 \\
\hline E. insignis (Kuhn) A.F. Tryon & $\operatorname{Tr}$ & Esax & 50207 \\
\hline Pityrogramma calomelanos (L.) Link & $\operatorname{Tr}$ & ER & 46540 \\
\hline Pteris decurrens $\mathrm{C}$. Presl & $\mathrm{Fl}$ & Esax & 46535 \\
\hline P. vittata $\mathrm{L}$. & $\operatorname{Tr}$ & $*$ & 42544 \\
\hline Vittaria graminifolia Kaulf. & $\mathrm{Fl}$ & ER & 46560 \\
\hline V. lineata (L.) Sm. & $\mathrm{Fl}$ & Eep & 46543 \\
\hline \multicolumn{4}{|l|}{ WOODSIACEAE (F. S. Souza, A. Salino) } \\
\hline Deparia petersenii (Kunze) M. Kato & $\mathrm{Fl}$ & ET & 46536 \\
\hline
\end{tabular}


Tabela1. Continuação...

\begin{tabular}{|c|c|c|c|}
\hline Famílias/Espécies & Habitat & Hábito & CESJ \\
\hline \multicolumn{4}{|c|}{ Angiospermas } \\
\hline \multicolumn{4}{|l|}{ ACANTHACEAE } \\
\hline Geissomeria schottiana Nees & $\mathrm{Fl}$ & Arb & 48911 \\
\hline Justicia riparia Kameyama & $\mathrm{Fl}$ & Arb & 42714 \\
\hline Ruellia elegans Poir. & $\mathrm{Fl}$ & Arb & 42258 \\
\hline \multicolumn{4}{|l|}{ ALSTROEMERIACEAE (J. A. Dutihl) } \\
\hline Alstroemeria cunha Vell. & $\operatorname{Tr}$ & ET & 42256 \\
\hline \multicolumn{4}{|l|}{ AMARANTHACEAE (M. S. Marchioretto) } \\
\hline Alternanthera brasiliana (L.) Kuntze & $\operatorname{Tr}$ & ET & 48550 \\
\hline Celosia corymbifera Didr. & $\operatorname{Tr}$ & ET & 48457 \\
\hline C. grandifolia Moq. & $\operatorname{Tr}$ & ET & 48546 \\
\hline \multicolumn{4}{|c|}{ APOCYNACEAE (C. N. Matozinhos, T. U. P. Konno) } \\
\hline Condylocarpon isthmicum (Vell.) DC. & $\operatorname{Tr}$ & Lia & 42867 \\
\hline \multicolumn{4}{|l|}{ ARACEAE (M. Nadruz) } \\
\hline Anthurium intermedium Kunth & $\operatorname{Tr}$ & ET & 47594 \\
\hline A. scandens (Aubl.) Engler & $\mathrm{Fl}$ & Eep & 42308 \\
\hline Anthurium sp. nov. & $\mathrm{Fl}$ & ET & 47472 \\
\hline Philodendron aff. inops Schott & $\mathrm{Fl}$ & Esax & 48473 \\
\hline P. cf. propinquum Schott & $\mathrm{Fl}$ & Eep & 42721 \\
\hline \multicolumn{4}{|l|}{ BEGONIACEAE (E. L. Jacques, L. Kollmann) } \\
\hline Begonia angularis Raddi & $\mathrm{Fl}$ & Arb & 42253 \\
\hline B. luxurians Scheidw. & $\mathrm{Fl}$ & ET & 42768 \\
\hline \multicolumn{4}{|l|}{ BROMELIACEAE (T. Mota, T. Trindade) } \\
\hline Aechmea bruggeri Leme & $\mathrm{Fl}$ & Eep & 42734 \\
\hline Billbergia distachya $\mathrm{Mez}$ & $\mathrm{Fl}$ & Eep & 42259 \\
\hline Pitcairnia flammea Lindl. & $\mathrm{Fl}$ & Esax & 53368 \\
\hline Quesnelia indecora $\mathrm{Mez}$ & $\mathrm{Fl}$ & Esax & 42323 \\
\hline Tillandsia gardneri Lindl. & $\mathrm{Tr} / \mathrm{Fl}$ & Eep & 42237 \\
\hline T. recurvata $(\mathrm{L}.) \mathrm{L}$. & $\operatorname{Tr}$ & Eep & 48659 \\
\hline T. tricholepis Baker & $\operatorname{Tr}$ & Eep & 48660 \\
\hline T. usneoides L. & $\operatorname{Tr}$ & Eep & 42233 \\
\hline Vriesea gradata $\mathrm{Mez}$ & $\mathrm{Fl}$ & Eep & 42849 \\
\hline$V$. modesta $\mathrm{Mez}$ & $\mathrm{Fl}$ & Eep & 42739 \\
\hline V. paraibica Wawra & $\mathrm{Fl}$ & Eep & 42309 \\
\hline V. vagans (L.B.Sm.) L.B.Sm. & $\mathrm{Fl}$ & Eep & 42676 \\
\hline \multicolumn{4}{|l|}{ CACTACEAE (J. A. Lombardi) } \\
\hline Lepismium houlletianum (Lem.) Barthlott & $\mathrm{Fl}$ & Eep & 46285 \\
\hline Rhipsalis elliptica G. Lindb. ex K. Schum. & $\mathrm{Fl}$ & Eep & 48275 \\
\hline R. pilocarpa Loefgren & $\mathrm{Fl}$ & Eep & 46270 \\
\hline R. teres Steud. & $\mathrm{Fl}$ & Eep & 46278 \\
\hline \multicolumn{4}{|l|}{ CANNACEAE } \\
\hline Canna indica $\mathrm{L}$. & $\mathrm{Fl}$ & ET & 42767 \\
\hline \multicolumn{4}{|l|}{ COMMELINACEAE } \\
\hline Dichorisandra thyrsiflora J.C.Mikan & $\mathrm{Fl}$ & ET & 48552 \\
\hline Sp1 & $\mathrm{Fl}$ & ET & 52850 \\
\hline \multicolumn{4}{|l|}{ CYPERACEAE (M. Alves) } \\
\hline Cyperus sp. & $\mathrm{Fl}$ & ET & 42310 \\
\hline Rhynchospora sp. 1 & $\mathrm{Fl}$ & ET & 42263 \\
\hline Rhynchospora sp.2 & $\operatorname{Tr}$ & ET & 46274 \\
\hline \multicolumn{4}{|l|}{ CUCURBITACEAE } \\
\hline Sp.1 & $\operatorname{Tr}$ & Lia & 46770 \\
\hline \multicolumn{4}{|l|}{ DILLENIACEAE } \\
\hline Davilla rugosa Poir. & $\operatorname{Tr}$ & Lia & 47463 \\
\hline
\end{tabular}


Tabela1. Continuação...

\begin{tabular}{|c|c|c|c|}
\hline Famílias/Espécies & Habitat & Hábito & CESJ \\
\hline \multicolumn{4}{|l|}{ DIOSCOREACEAE } \\
\hline Dioscorea filiformis Griseb. & $\mathrm{Fl}$ & Lia & 47459 \\
\hline \multicolumn{4}{|l|}{ ERIOCAULACEAE (M. L. O. Trovó) } \\
\hline Blastocaulon prostratum Ruhland & $\operatorname{Tr}$ & ET & 42342 \\
\hline Paepalanthus cf. acuminatus Ruhland & $\operatorname{Tr}$ & ET & 42242 \\
\hline P. manicatus Poulsen & $\mathrm{Fl}$ & Esax & 42165 \\
\hline P. plantagineus Körn. & $\operatorname{Tr}$ & Esax & 46279 \\
\hline \multicolumn{4}{|l|}{ EUPHORBIACEAE } \\
\hline Chamaesyce sp. & $\operatorname{Tr}$ & Esax & 48545 \\
\hline Dalechampia micromeria Baill. & $\operatorname{Tr}$ & Lia & 42865 \\
\hline Phyllanthus rosellus Müll. Arg. & & ET & 42246 \\
\hline \multicolumn{4}{|l|}{ GESNERIACEAE (J. G. Blaser, A. Chautems) } \\
\hline Nematanthus crassifolius (Schott) Wiehler & $\mathrm{Fl}$ & Eep & 42325 \\
\hline Sinningia tuberosa (Mart.) H.E. Moore & $\mathrm{Fl}$ & ER & 53369 \\
\hline Vanhouttea hilariana Chautems & $\operatorname{Tr}$ & Arb & 53365 \\
\hline \multicolumn{4}{|l|}{ IRIDACEAE } \\
\hline Neomarica rupestris (Ravenna) N.S.Chukr & $\mathrm{Tr} / \mathrm{Fl}$ & Esax & 43276 \\
\hline \multicolumn{4}{|l|}{ LAMIACEAE } \\
\hline Eriope sp. & $\operatorname{Tr}$ & Arb & 53388 \\
\hline Sp. 1 & $\operatorname{Tr}$ & Arb & 53364 \\
\hline \multicolumn{4}{|l|}{ LAURACEAE (L. C. S. Assis) } \\
\hline Ocotea tristis Mart. ex Nees & $\operatorname{Tr}$ & Arb & 42852 \\
\hline \multicolumn{4}{|l|}{ LORANTHACEAE (C.Reif) } \\
\hline Struthanthus marginatus (Desr. ) G.Don & $\operatorname{Tr}$ & Ppar & 42178 \\
\hline \multicolumn{4}{|l|}{ MARANTACEAE } \\
\hline Calathea sp. & $\mathrm{Fl}$ & ET & 48474 \\
\hline Sp.1 & $\mathrm{Fl}$ & ET & 46692 \\
\hline \multicolumn{4}{|l|}{ MARCGRAVIACEAE } \\
\hline Marcgravia polyantha Delp. & $\mathrm{Tr} / \mathrm{Fl}$ & Arb & 48980 \\
\hline \multicolumn{4}{|l|}{ MELASTOMATACEAE (R. Goldenberg) } \\
\hline Comolia sertularia Triana & $\operatorname{Tr}$ & Arb & 46690 \\
\hline Sp.1 & $\mathrm{Fl}$ & Arb & 48983 \\
\hline \multicolumn{4}{|l|}{ MORACEAE (S. Romaniuc Neto, R. M. Castro) } \\
\hline Dorstenia capricorniana Carauta, C. Valente \& Sucre & $\mathrm{Fl}$ & ET & 46272 \\
\hline \multicolumn{4}{|l|}{ MYRTACEAE (K. Antunes, M. Sobral) } \\
\hline Eugenia cf. prasina O. Berg & $\mathrm{Fl}$ & Arb & 42326 \\
\hline Myrcia guianensis DC. & $\operatorname{Tr}$ & Arb & 46281 \\
\hline \multicolumn{4}{|l|}{ OCHNACEAE } \\
\hline Sauvagesia erecta $\mathrm{L}$. & $\operatorname{Tr}$ & ET & 48662 \\
\hline \multicolumn{4}{|l|}{ ORCHIDACEAE (N. L. Abreu, L. Menini Neto) } \\
\hline Cattleya loddigesii Lindl. & $\mathrm{Tr} / \mathrm{Fl}$ & Eep & 48916 \\
\hline Campylocentrum cf. robustum Cogn. & $\mathrm{Fl}$ & Eep & 53362 \\
\hline Cyclopogon warmingii (Rchb. f. \& Warm.) Schltr. & $\mathrm{Fl}$ & ET & 42727 \\
\hline Cirrhaea sp. & $\mathrm{Fl}$ & Esax & 53359 \\
\hline Cyrtopodium cardiochilum Lindl. & $\operatorname{Tr}$ & Esax & 51836 \\
\hline Dichaea aff. anchorifera Cogn. & $\mathrm{Fl}$ & Eep & 42726 \\
\hline Elleanthus brasiliensis Rchb. f. & $\operatorname{Tr}$ & Esax & 47376 \\
\hline Encyclia patens Hook. & $\mathrm{Tr} / \mathrm{Fl}$ & Eep & 42319 \\
\hline Epidendrum avicula Lindl. & $\mathrm{Tr} / \mathrm{Fl}$ & Eep & 42320 \\
\hline E. densiflorum Hook. & $\mathrm{Fl}$ & Esax & 47382 \\
\hline E. difforme Jacq. & $\operatorname{Tr}$ & Eep & 47847 \\
\hline E. ochrochlorum Barb. Rodr. & $\mathrm{Fl}$ & Eep & 47486 \\
\hline Eurystyles actinosophila (Barb. Rodr.) Schltr. & $\mathrm{Fl}$ & Eep & 53361 \\
\hline
\end{tabular}


Tabela1. Continuação...

\begin{tabular}{|c|c|c|c|}
\hline Famílias/Espécies & Habitat & Hábito & CESJ \\
\hline Gomesa recurva Lodd. & $\mathrm{Fl}$ & Eep & 42339 \\
\hline Hoffmannseggella crispata (Thunb.) H.G.Jones & $\operatorname{Tr}$ & Esax & 42330 \\
\hline Isochilus linearis (Jacq.) R. Br. & $\mathrm{Fl}$ & Eep & 47391 \\
\hline Liparis nervosa (Thunb.) Lindl. & $\operatorname{Tr}$ & ET & 48478 \\
\hline Masdevallia infracta Lindl. & $\mathrm{Fl}$ & Eep & 47373 \\
\hline Maxillaria bradei Schltr. ex Hoehne & $\mathrm{Fl}$ & Eep & 46605 \\
\hline Oncidium hookeri Rolfe & $\operatorname{Tr}$ & Eep & 48915 \\
\hline$O$. aff. pubes Lindl. & $\mathrm{Fl}$ & Eep & 48913 \\
\hline Pleurothallis hypnicola Lindl. & $\mathrm{Fl}$ & Eep & 42733 \\
\hline Polystachya estrellensis Rchb. f. & $\mathrm{Tr} / \mathrm{Fl}$ & Eep & 42324 \\
\hline Prescottia montana Barb. Rodr. & $\operatorname{Tr}$ & ET & 42813 \\
\hline Stelis intermedia Poepp. \& Endl. & $\mathrm{Fl}$ & Eep & 48230 \\
\hline Stigmatosema polyaden (Vell.) Garay & $\mathrm{Fl}$ & ET & 50870 \\
\hline Zygopetalum mackaii Hook. & $\operatorname{Tr}$ & Esax & 42329 \\
\hline \multicolumn{4}{|l|}{ PASSIFLORACEAE (A. C. M. Pires) } \\
\hline Passiflora cf. haematostigma Mart. ex Mast. & $\operatorname{Tr}$ & Lia & 52848 \\
\hline \multicolumn{4}{|l|}{ PHYTOLACCACEAE (M. S. Marchioretto) } \\
\hline Microtea paniculata Moq. & $\operatorname{Tr}$ & ET & 42260 \\
\hline \multicolumn{4}{|l|}{ PIPERACEAE (E. F. Guimarães) } \\
\hline Peperomia alata Ruiz \& Pav. & $\mathrm{Fl}$ & Esax & 42262 \\
\hline P. blanda Kunth & $\mathrm{Fl}$ & Esax & 47593 \\
\hline P. galioides Kunth & $\mathrm{Tr} / \mathrm{Fl}$ & Esax & 46267 \\
\hline P.pseudoestrellensis C.DC. & $\mathrm{Fl}$ & Eep & 42334 \\
\hline P. rotundifolia $($ L.) Kunth & $\mathrm{Fl}$ & Eep & 46280 \\
\hline P. trinervis Ruiz \& Pav. & $\mathrm{Fl}$ & Eep & 46284 \\
\hline P. urocarpa Fisch. \& C.A.Mey. & $\mathrm{Fl}$ & Esax & 48551 \\
\hline Piper anisum (Spreng.) Angely & $\mathrm{Fl}$ & Arb & 46266 \\
\hline P. caldense C. DC. & $\mathrm{Fl}$ & Arb & 42710 \\
\hline P. coccoloboides Kunth & $\mathrm{Fl}$ & Arb & 42869 \\
\hline P. tectoniifolium (Kunth) Steud. & $\mathrm{Fl}$ & Arb & 46264 \\
\hline \multicolumn{4}{|l|}{ POACEAE (F. M. Ferreira, P. L. Viana) } \\
\hline Parodiolyra micrantha (Kunth) Davidse \& Zuloaga & $\mathrm{Fl}$ & ET & 23469 \\
\hline \multicolumn{4}{|l|}{ RUBIACEAE (J. Amaral) } \\
\hline Palicourea marcgravii A. St.-Hil. & $\mathrm{Fl}$ & Arb & 46767 \\
\hline Psychotria leiocarpa Cham. \& Schltdl. & $\mathrm{Fl}$ & Subarb & 48997 \\
\hline Psychotria sp. & $\mathrm{Fl}$ & Arb & 52834 \\
\hline \multicolumn{4}{|l|}{ SAPINDACEAE (K. F. Silva, J. Miloski, A. Valente) } \\
\hline Paullinia carpopoda Cambess. & $\operatorname{Tr}$ & Lia & 47466 \\
\hline Serjania paradoxa Radlk. & $\operatorname{Tr}$ & Lia & 47323 \\
\hline Serjania sp. & $\operatorname{Tr}$ & Lia & 48984 \\
\hline \multicolumn{4}{|l|}{ SOLANACEAE (E. A. Feliciano, J. R. Stehmann) } \\
\hline Aureliana fasciculata Sendtn. & $\mathrm{Fl}$ & Arb & 46283 \\
\hline \multicolumn{4}{|l|}{ URTICACEAE } \\
\hline Urera baccifera (L.) Gaudich. & $\operatorname{Tr}$ & ET & 48786 \\
\hline \multicolumn{4}{|l|}{ VELLOZIACEAE (R. Mello-Silva) } \\
\hline Vellozia albiflora Pohl & $\operatorname{Tr}$ & Esax & 42318 \\
\hline \multicolumn{4}{|l|}{ VITACEAE (J.A.Lombardi) } \\
\hline Cissus albida Cambess. & $\operatorname{Tr}$ & Lia & 46773 \\
\hline C. verticillata (L.) Nicolson \& C.E. Jarvis & $\operatorname{Tr}$ & Lia & 46772 \\
\hline
\end{tabular}

Habitat: $\mathrm{Tr}$ - transição de floresta com campo rupestre, $\mathrm{Fl}$ - interior da floresta, $\mathrm{Cr}$ - campo rupestre. Hábito: Arb - Arbusto, Eep - Erva epífita, Esax - Erva saxícola, ER - Erva rupícola, ET - Erva terrestre, Hem - Hemiepífita, Lia - Liana, Ppar - Planta hemiparasita, Subar - Sub-Arbusto, * planta encontrada sobre muro de concreto. Especialistas consultados estão entre parênteses após a respectiva família.

Habitat: $\mathrm{Tr}$ - transition between forest and campo rupestre, $\mathrm{Fl}$ - forest interior, $\mathrm{Cr}$ - campo rupestre. Habit: Arb - Shrub, Eep - Epiphyte herb, Esax Saxicole herb, ER - litophytic herb, ET - Terrestrial herb, Hem - Hemiepiphyte, Lia - liana, Ppar - Hemiparasitic plant, Subar - Sub-shrub, * plant found on a concrete wall. Specialists that contribute with identifications are cited between parentheses, after the respective family. 

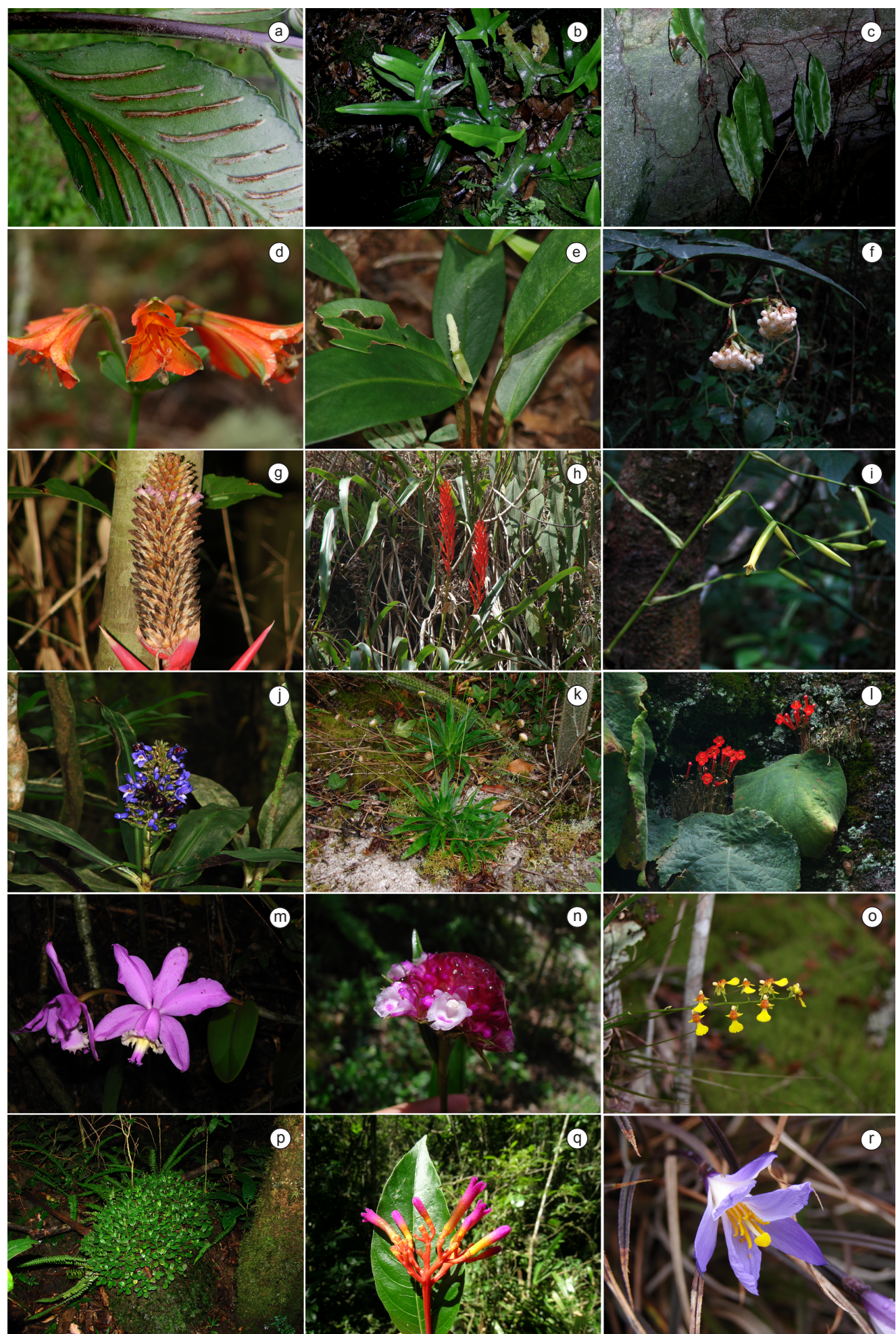

Figura 4. Algumas espécies ocorrentes no interior do Cânion do Ribeirão do Funil. a-c - Pteridófitas: a. Aspleniaceae, Asplenium oligophyllum; b. Pteridaceae, Doryopteris sagittifolia; c. Oleandraceae, Oleandra hirta. d-r - Angiospermas: d. Alstroemeriaceae, Alstroemeria cunha; e. Araceae, Anthurium scandens; f. Begoniaceae, Begonia angularis; g-i. Bromeliaceae, g. Aechmea bruggeri, h. Pitcairnia flammea, i. Vriesea vagans; j. Commelinaceae, Dichorisandra thyrsiflora; k. Eriocaulaceae, Paepalanthus elongatus; 1 . Gesneriaceae, Sinningia tuberosa; m-o. Orchidaceae, m. Cattleya loddigesii, n. Elleanthus brasiliensis, o. Oncidium hookeri; p. Piperaceae, Peperomia martiana; q. Rubiaceae, Palicourea marcgravii; r. Velloziaceae, Vellozia albiflora.

Figure 4. Some species occurring in the interior of Cânion do Ribeirão do Funil. a-c - Pteridófitas: a. Aspleniaceae, Asplenium oligophyllum; b. Pteridaceae, Doryopteris sagittifolia; c. Oleandraceae, Oleandra hirta. d-r - Angiospermas: d. Alstroemeriaceae, Alstroemeria cunha; e. Araceae, Anthurium scandens; f. Begoniaceae, Begonia angularis; g-i. Bromeliaceae, g. Aechmea bruggeri, h. Pitcairnia flammea, i. Vriesea vagans; j. Commelinaceae, Dichorisandra thyrsiflora; k. Eriocaulaceae, Paepalanthus elongatus; 1 . Gesneriaceae, Sinningia tuberosa; m-o. Orchidaceae, m. Cattleya loddigesii, n. Elleanthus brasiliensis, o. Oncidium hookeri; p. Piperaceae, Peperomia martiana; q. Rubiaceae, Palicourea marcgravii; r. Velloziaceae, Vellozia albiflora. 
resta, mas com representantes também na transição da floresta com o campo rupestre (Figura 4).

As pteridófitas compreenderam 10 famílias, reunindo 39 espécies e duas variedades, destacando-se Pteridaceae com o maior número de espécies (11 espécies), seguida de Polypodiaceae (nove espécies), Aspleniaceae (seis espécies e duas variedades) e Dryopteridaceae (quatro espécies). Assim 77\% das pteridófitas estão agrupadas em apenas quatro famílias. O gênero com maior riqueza específica é Asplenium com seis espécies e duas variedades, seguido de Doryopteris, Elaphoglossum e Serpocaulon (três espécies cada).

As angiospermas foram representadas por 116 espécies, distribuídas em 38 famílias. As famílias mais ricas são Orchidaceae (apresentando 27 espécies), seguida por Bromeliaceae (12), Piperaceae (11), Araceae (cinco), Cactaceae e Eriocaulaceae (quatro espécies cada). Desse modo, apenas seis famílias concentraram um total de $54 \%$ das angiospermas registradas no cânion. Os gêneros mais representativos foram Peperomia (com sete espécies), seguido por Epidendrum, Piper, Tillandsia e Vriesea (quatro espécies cada).

O hábito herbáceo foi o mais representativo, com 124 espécies (79\% das espécies registradas), distribuídas da seguinte forma: 45 ervas terrestres, 42 ervas epífitas, 23 ervas saxícolas, 20 ervas rupícolas e apenas uma hemiepífita. Deve ser destacado que nove espécies (todas pertencentes às pteridófitas) podem apresentar mais de um hábito. Foram também encontradas espécies arbustivas (21 espécies), lianescentes (10 espécies) e apenas uma espécie hemiparasita.

As epífitas, que corresponderam a aproximadamente um terço das espécies herbáceas (42 espécies), estão distribuídas em apenas sete famílias: Orchidaceae (17 espécies), Bromeliaceae (10), Polypodiaceae (cinco), Cactaceae (quatro), Piperaceae (três), Araceae (duas) e Pteridaceae (apenas uma espécie).

Dentre as pteridófitas registradas na Serra Negra, são de ocorrência exclusiva no Cânion do Ribeirão do Funil (observações pessoais): Adiantopsis radiata, Anemia sp., Asplenium radicans var. partitum, Blechnum gracile, Deparia petersenii, Doryopteris sagittifolia, Elaphoglossum glaziovii, Eriosorus biardii, E. insignis, Microgramma tecta, Olfersia cervina, Pityrogramma calomelanos, Pteris vittata e Selaginella tenuissima. As angiospermas também apresentam espécies exclusivas do Cânion, em comparação com a flora do restante da Serra Negra: Anthurium sp. nov., Cattleya loddigesii, Cirrhaea sp., Cyclopogon warmingii, Cyrtopodium cardiochilum, Dichaea aff. anchorifera, Elleanthus brasiliensis, Epidendrum avicula, E. densiflorum, Hoffmannseggella crispata, Liparis nervosa, Maxillaria bradei, Oncidium aff. pubes, Philodendron cf. propinquum, Pleurothallis grobyi, P. hypnicola, Rhipsalis pilocarpa, Stigmatosema polyaden e Vriesea paraibica.

Doze espécies encontradas na área são citadas na lista vermelha de espécies ameaçadas de extinção do estado de Minas Gerais (Biodiversitas 2007), com status variado, segundo os critérios propostos pela IUCN 2001 (International Union for Conservation of Nature and Natural Resources): Aechmea bruggeri (Bromeliaceae) como Criticamente em Perigo (CR), endêmica da Serra Negra e adjacências; Rhipsalis pilocarpa (Cactaceae), Cattleya loddigesii, Epidendrum ochrochlorum, Hoffmannseggella crispata (Orchidaceae) e Vanhouttea hilariana (Gesneriaceae) como Em Perigo (EN), endêmica da região; Nematanthus crassifolius (Gesneriaceae), Neomarica rupestris (Iridaceae), Pecluma chnoophora (Polypodiaceae) e Sinningia tuberosa (Gesneriaceae) como Vulnerável (VU); Peperomia urocarpa (Piperaceae) como Quase Ameaçada (NT); Oleandra hirta como Deficiente de Dados (DD).

\section{Discussão}

Apesar da área reduzida ocupada pelo Cânion do Ribeirão do Funil (0,9 ha), este fragmento se destaca pela riqueza específica de plantas vasculares encontradas até o momento, contribuindo com 15-20\% das espécies registradas para toda a área de estudo da Serra Negra e adjacências (observações pessoais), constituída de cerca de 10.000 ha. Além da destacada importância em número de espécies, qualitativamente também deve ser ressaltada a contribuição do Cânion na flora da Serra Negra, com pelo menos 34 espécies exclusivas deste fragmento, dentre as quais, duas pteridófitas que são paleotropicais introduzidas: Pteris vitatta e Deparia petersenii (Salimena et al., dados não publicados).

Dentre as famílias mais ricas em espécies no Cânion do Ribeirão do Funil, o posicionamento das duas primeiras, Orchidaceae e Bromeliaceae, se justifica em virtude de a floresta atlântica ser um dos centros de diversidade de ambas as famílias conforme destacam Martinelli et al. (2008) e Pabst \& Dungs (1975). Piperaceae figura entre as mais representativas principalmente pela contribuição de Peperomia com sete espécies, o gênero mais rico na área estudada, apresentando maior diversidade em áreas de Floresta Ombrófila Densa (Carvalho-Silva \& Guimarães 2008). Pteridaceae apresenta ampla distribuição geográfica e, embora ocorra em um espectro diversificado de ambientes, é bem representada em ambientes florestais (Tryon \& Tryon 1982), enquanto Polypodiaceae se destaca principalmente por ser uma das famílias de plantas vasculares com o maior número de espécies epífitas garantindo a sua presença entre as famílias mais ricas (Smith et al. 2006, Haufler 2007).

Estudos semelhantes em formações florestais no domínio atlântico abrangendo todas as formas de vida de plantas vasculares nãoarbóreas são inexistentes, exceto para a Floresta Ombrófila Densa da Reserva da Cidade Universitária Armando Salles de Oliveira (CUASO), no município de São Paulo (Dislich \& Mantovani 1998, Groppo \& Pirani 2005). O número de espécies encontradas no Cânion (157 em 0,9 ha) pode ser considerado alto, quando em comparação com a CUASO (217 em 10 ha), no entanto a composição das cinco famílias mais representativas no Cânion não coincide com as famílias mais ricas da Reserva da CUASO: Asteraceae (22 spp.), Araceae (11 spp.), Bignoniaceae, Orchidaceae, Poaceae e Polypodiaceae (10 spp. cada). Esta diferença na composição de famílias entre as áreas pode resultar de particularidades na composição florística de plantas vasculares não-arbóreas ou de uma possível intervenção humana na Reserva da CUASO que causou a redução de representantes de famílias tipicamente ricas nesta formação vegetacional, tais como Bromeliaceae e Orchidaceae, que são muito visadas por coletores e colecionadores, conduzindo a uma interpretação incorreta das relações florísticas entre as áreas.

A ocorrência de Asteraceae como a família mais rica em espécies na Reserva da CUASO se dá em virtude do grande número de plantas lianescentes na borda da mata (nove spp.), sugerindo que a fragmentação altera a composição florística do remanescente florestal, conduzindo a uma possível explicação para o reduzido número de espécies de Orchidaceae e Bromeliaceae. Além disso, o Cânion do Ribeirão do Funil apresenta-se em alto grau de preservação, com grande representatividade em ambas as famílias, que juntas compreendem mais de $33 \%$ das angiospermas e $25 \%$ de todas as espécies de plantas vasculares não-arbóreas da área estudada.

Embora não existam inventários abrangendo todos os hábitos de plantas vasculares na região, aparentemente há pouca relação entre o tipo vegetacional e a composição das famílias mais representativas de plantas não-arbóreas. Esta afirmativa é corroborada pelos resultados obtidos por Meira-Neto \& Martins (2000), Kozera \& Rodrigues (2005), Pifano (2007), Pifano et al. (2007), Kozera et al. (2009) que encontraram como famílias mais ricas em seus inventários, respectivamente, Rubiaceae e Fabaceae, Dryopteridaceae, Orchidaceae, Asteraceae e Dryopteridaceae. Esta baixa relação entre famílias mais diversas e tipo vegetacional também foi observada por Menini Neto 
et al. (2009) em análise de similaridade das angiospermas epífitas em 24 áreas das regiões Sudeste e Sul do Brasil.

A ocorrência do estrato herbáceo como o mais representativo em número de espécies neste trabalho corrobora os resultados obtidos por Kozera \& Rodrigues (2005) e Kozera et al. (2009) em áreas de Floresta Ombrófila Densa no estado no estado do Paraná, ainda que nos referidos estudos as espécies epífitas tenham sido excluídas de sua análise. Gentry \& Dodson (1987a), em Floresta Ombrófila Densa no Equador, também encontraram as plantas herbáceas como mais representativas. No entanto, a porcentagem de espécies herbáceas observadas no Cânion (ca. 79\%) supera consideravelmente os três trabalhos supracitados. Por outro lado, outras áreas florestais podem apresentar como hábito mais destacado as lianas, como encontrado por Groppo \& Pirani (2005) e Pifano (2007) ou os arbustos (Pifano et al. 2007), mas nos dois últimos trabalhos foram excluídas as pteridófitas da análise.

Destacam-se no Cânion do Ribeirão do Funil as plantas epífitas com 42 espécies, dentre as quais 37 são pertencentes a apenas cinco famílias (Orchidaceae, Bromeliaceae, Polypodiaceae, Piperaceae e Araceae), consideradas por Kress (1986) e Benzing (1990) as mais ricas em espécies epifíticas dentre as plantas vasculares. Quatro destas cinco famílias (excluindo Araceae) figuram entre as mais representativas no Cânion do Ribeirão do Funil, destacando a importância do hábito epifítico neste fragmento florestal. O resultado obtido neste trabalho está de acordo com vários inventários da flora vascular epifítica no domínio atlântico, nos quais Orchidaceae comumente ocupa o primeiro lugar, em geral seguida por Bromeliaceae e Polypodiaceae, embora o posicionamento das duas últimas possa variar na ocupação do segundo e terceiro lugares (Waechter 1986, Borgo \& Silva 2003, Rogalski \& Zanin 2003, Giongo \& Waechter 2004, Hefler \& Faustioni 2004, Gaiotto \& Acra 2005, Menini Neto et al. 2009).

A porcentagem de espécies epífitas no Cânion (cerca de 26\%) pode ser considerada alta, uma vez que a proporção conhecida de plantas de hábito epifítico geralmente encontrada nos inventários florísticos em ambientes úmidos gira em torno de $10 \%$ de todas as plantas vasculares, como destacado por Kress (1986), Gentry \& Dodson (1987a, 1987b) e Benzing (1987, 1990). No presente trabalho apenas $15 \%$ das pteridófitas apresentaram hábito epifítico, valor baixo quando comparadas com os $48 \%$ presentes em Macaé de Cima, Rio de Janeiro (Sylvestre 1997) e 62\% na Serra do Mar do Paraná (Dittrich et al. 2005). Por outro lado, essa porcentagem é consideravelmente superior quando comparada com os $8 \%$ encontrados em dois fragmentos florestais da Área de Proteção Ambiental Fernão Dias, em Minas Gerais (Melo \& Salino 2007).

O número elevado de espécies herbáceas, em especial de epífitas, se deve à existência de um microhabitat específico nestas regiões de grotas, muito diferenciado do ambiente existente na vegetação campestre circundante. Uma das características determinantes é a alta umidade disponível, aliada a altitudes elevadas, que estabelecem condições essenciais para a alta frequiência de espécies epífitas (Gentry \& Dodson 1987b, Benzing 1990).

Em conclusão, a intensa visitação ao Vilarejo do Funil, sobretudo em períodos festivos, aliada ao número expressivo de espécies ameaçadas de extinção e à presença de porções únicas da biodiversidade da Serra Negra, incluindo espécies endêmicas da região (presentes no Cânion do Ribeirão do Funil), ressaltam a necessidade da implantação de um plano de ação que vise à proteção das espécies ocorrentes neste habitat extremamente frágil.

\section{Agradecimentos}

À FAPEMIG, pela concessão de auxílio ao projeto "Estudos Florísticos na Serra Negra, Minas Gerais” (CRA 1891/06 e CRA
1810-5.02/07) e pela concessão de bolsa de Iniciação Científica a N. L. Abreu. Ao Sr. Ceslau Gomes Ferreira Freitas, proprietário da área de estudo, que permitiu a realização deste trabalho. A Leandro Cézanne de Souza Assis pelo auxílio com o abstract. A Márcio Malafaia pela confecção do mapa. Aos revisores pelas sugestões e correções.

\section{Referências Bibliográficas}

ALVES, R.J.V. \& KOLBEK, J. 2009. Summit vascular flora of the Serra de São José, Minas Gerais, Brazil. Check List. 5(1):35-73

ANDRADE, P.M. 1992. Estrutura do estrato herbáceo de trechos da Reserva Biológica Mata do Jambreiro, Nova Lima, Minas Gerais. Campinas. Dissertação de Mestrado, Universidade Estadual de Campinas, Campinas.

Angiosperm Phylogeny Group II - APGII. 2003. An update of the Angiosperm Phylogeny Group Classification for the orders and families of flowering plants: APGII. Bot. J. Linn. Soc. 141:399-436.

ARAÚJO, G.M., BARBOSA, A.A.A., ARANTES, A.A. \& AMARAL, A.F. 2002. Composição florística de veredas no município de Uberlândia, MG. Rev. Bras. Bot. 25(4):475-493.

BENZING, D.H. 1987. Vascular epiphytism: taxonomic participation and adaptive diversity. Ann. Missouri Bot. Gard. 74(2):183-204.

BENZING, D.H. 1990. Vascular epiphytes. Cambridge University Press, Cambridge.

van den BERG, E. \& OLIVEIRA-FILHO, A.T. 2000. Composição florística e estrutura fitossociológica de uma floresta ripária em Itutinga, MG, e comparação com outras áreas. Rev. Bras. Bot. 23(3):231-253.

BERNACCI, L.C. 1992. Estudo florístico e fitossociológico de uma floresta no município de Campinas, com ênfase nos componentes herbáceo e arbustivo. Dissertação de Mestrado, Universidade Estadual de Campinas, Campinas.

Biodiversitas. 2007. Revisão das listas das espécies da flora e da fauna ameaçadas de extinção do estado de Minas Gerais. Fundação Biodiversitas, Belo Horizonte, p. 37-104. (Relatório final, v. 2). http://www.biodiversitas. org.br/listas-mg (último acesso em 20/07/2009).

BORGO, M., SILVA, S.M. \& PETEAN, M.P. 2002. Epífitos vasculares em um remanescente de Floresta Estacional Semidecidual, no município de Fênix, PR, Brasil. Acta Biol. Leopold. 24(2):121-130.

BORGO, M. \& SILVA, S.M. 2003. Epífitos vasculares em fragmentos de Floresta Ombrófila Mista, Curitiba, Paraná, Brasil. Rev. Bras. Bot. 26(3):391-401.

CÂMARA, I.G. 2005. Breve história da conservação da mata atlântica. In Mata Atlântica: biodiversidade, ameaças e perspectivas (C. Galindo-Leal \& I.G. Câmara, eds.). Conservação Internacional, Belo Horizonte, p. 31-42.

CARVALHO-SILVA, M. \& GUIMARÃES, E.F. 2008. Peperômia ciliatocaespitosa M. Carvalho-Silva \& E. F. Guim. (Piperaceae): uma nova espécie para o Brasil. Acta Bot. Bras. 22(2):559-531.

COSTA, C.M.R., HERMANN, G., MARTINS, C.S., LINS, L.V. \& LAMAS, I. 1998. Biodiversidade em Minas Gerais: um atlas para sua conservação. Fundação Biodiversitas, Belo Horizonte.

DALANESI, P.E., OLIVEIRA-FILHO, A.T. \& FONTES, M.A.L. 2004. Flora e estrutura do componente arbóreo da floresta do Parque Ecológico Quedas do Rio Bonito, Lavras, MG, e correlações entre a distribuição das espécies e variáveis ambientais. Acta Bot. Bras. 18(4):737-757.

DIAS, H.C.T., FERNANDES-FILHO, E.I., SCHAEFER, C.E.G.R., FONTES, L.E.F. \& VENTORIM, L.B. 2002. Geoambientes do Parque Estadual do Ibitipoca, município de Lima Duarte-MG. Rev. Árvore 26(6):777-786.

DIESEL, S. \& SIQUEIRA, J.C. 1991. Estudo fitossociológico herbáceo/ arbustivo da mata ripária da bacia hidrográfica do Rio dos Sinos, Rio Grande do Sul. Pesquisas 42(2):205-257.

DISLICH, R. \& MANTOVANI, W. 1998. A flora de epífitas vasculares da Reserva da Cidade Universitária "Armando Salles Oliveira” (São Paulo, Brasil). Bol. Bot. 17(1):61-83. 
DITTRICH, V.A.O., WAECHTER, J.L. \& SALINO, A. 2005. Species richness of pteridophytes in a montane Atlantic rain forest plot of Southern Brazil. Acta Bot. Bras. 19(3):519-525.

DRUMMOND, G.M., MARTINS, C.S., MACHADO, A.B.M., SEBAIO, F.A. \& ANTONINI, Y. 2005. Biodiversidade em Minas Gerais, um atlas para sua conservação. 2 ed. Fundação Biodiversitas, Belo Horizonte.

Empresa de Assistência Técnica e Extensão Rural do Estado de Minas Gerais EMATER. 2003. Projeto APA da Serra do Funil. EMATER, Rio Preto.

FILGUEIRAS, T.S., NOGUEIRA, P.E., BROCHADO, A.L. \& GUALA, G.F. 1994. Caminhamento: um método expedito para levantamentos florísticos qualitativos. Cad. Geocienc. 12(1):39-43.

FRANÇA, G.S. \& STEHMANN, J.R. 2004. Composição florística e estrutura do componente arbóreo de uma floresta altimontana no município de Camanducaia, Minas Gerais, Brasil. Rev. Bras. Bot. 27(1):19-30.

GAIOTTO, D.F. \& ACRA, L.A. 2005. Levantamento qualitativo de epífitos da Fazenda Gralha Azul - Fazenda Rio Grande - Paraná. Rev. Estud. Biol. 27(60):25-32.

GALINDO-LEAL, C. \& CÂMARA, I.G. 2005. Status do hotspot Mata Atlâtnica: uma síntese. In Mata Atlântica: biodiversidade, ameaças e perspectivas (C. Galindo-Leal \& I.G. Câmara, eds.). Conservação Internacional, Belo Horizonte, p. 3-11.

GENTRY, A.H. \& DODSON, C.H. 1987a. Contribution on nontrees to species richness of a tropical rain forest. Biotropica. 19(2):149-156.

GENTRY, A.H. \& DODSON, C.H. 1987b. Diversity and biogeography of neotropical vascular epiphytes. Ann. Missouri Bot. Gard. 74(2):205-233.

GIONGO, C. \& WAECHTER, J.L. 2004. Composição florística e estrutura comunitária de epífitos vasculares em uma floresta de galeria na Depressão Central do Rio Grande do Sul. Rev. Bras. Bot. 27(3):563-572.

GIULIETTI, A.M., MENEZES, N.L., PIRANI, J.R., MEGURO, M. \& WANDERLEY, M.G.L. 1987. Flora da Serra do Cipó, Minas Gerais: caracterização e lista das espécies. Bol. Bot. 9(1):1-151

GROPPO, M. \& PIRANI, J.R. 2005. Levantamento florístico das espécies de ervas, subarbustos, lianas e hemiepífitas da mata da Reserva da Cidade Universitária "Armando Salles Oliveira", São Paulo, SP, Brasil. Bol. Bot. 23(2):141-233.

HAUFLER, C.H. 2007. Genetics, phylogenetics and biogeography: considering how shifting paradigms and continents influence fern diversity. Brittonia. 59(2):108-114.

HEFLER, S.M. \& FAUSTIONI, P. 2004. Levantamento florístico de epífitos vasculares do Bosque São Cristóvão - Curitiba - Paraná - Brasil. Rev. Estud. Biol. 26(54):11-19.

HOLMGREN, P.K. \& HOLMGREN, N.H. 1998. Index Herbariorum: a global directory of public herbaria and associated staff. New York Botanical Garden's Virtual Herbarium, New York. http://sweetgum.nybg.org/ih/ (último acesso em 31/01/2009).

International Union for Conservation of Nature and Natural Resources - IUCN. 2001. IUCN Red List Categories and Criteria. Version 3.1. IUCN Species Survival Commission, Cambridge.

KOZERA, C. \& RODRIGUES, R.R. 2005. Floresta Ombrófila Densa Submontana: florística e estrutura do estrato inferior. In História natural e conservação da Ilha do Mel (M.C.M. Marques \& R.M. Britez, orgs.). Universidade Federal do Paraná, Curitiba, p. 103-122.

KOZERA, C., RODRIGUES, R.R. \& DITTRICH, V.A.O. 2009. Composição florística do sub-bosque de uma floresta ombrófila densa Montana, Morretes, PR, Brasil. Floresta. 39(2):323-334.

KRESS, W.J. 1986. The systematic distribution of vascular epiphytes: an update. Selbyana. 9:2-22

LOMBARDI, J.A., SALINO, A. \& TEMPONI, L.G. 2005. Diversidade florística de plantas vasculares no município de Januária, Minas Gerais, Brasil. Lundiana. 6(1):3-20.

LOPES, W.P., PAULA, A., SEVILHA, A.C. \& SILVA, A.F. 2002. Composição da flora arbórea de um trecho de floresta estacional no Jardim Botânico da Universidade Federal de Viçosa (face sudoeste), Viçosa, Minas Gerais. Rev. Árvore 26(3):339-347.
MARANGON, L.C., SOARES, J.J. \& FELICIANO, A.L.P. 2003. Florística arbórea da Mata da Pedreira, município de Viçosa, Minas Gerais. Rev. Árvore 27(2):207-215.

MARTINELLI, G., VIEIRA, C.M., GONZALEZ, M., LEITMAN, P., PIRATININGA, A., COSTA, A.F. \& FORZZA, R.F. 2008. Bromeliaceae da Mata Atlântica brasileira: lista de espécies, distribuição e conservação. Rodriguésia. 59(1):209-258.

MEIRA-NETO, J.A.A. \& MARTINS, F.R. 2000. Composição florística do estrato herbáceo-arbustivo de uma floresta estacional semidecidual em Viçosa-MG. Rev. Árvore. 24(4):407-416.

MELO, L.C.N. \& SALINO, A. 2007. Pteridófitas em fragmentos florestais da APA Fernão Dias, Minas Gerais, Brasil. Rodriguésia. 58(1):207-220.

MENINI NETO, L., FORZZA, R.C. \& ZAPPI, D. 2009. Angiosperm epiphytes as conservation indicators in forest fragments: a case study from southeastern Minas Gerais, Brazil. Biodivers Conserv. 18(14): 3785-3807.

MORELLATO, L.P.C. \& HADDAD, C.F.B. 2000. Introduction: the Brazilian Atlantic Forest. Biotropica. 32(4b):786-792.

MORI, S., MATTOS-SILVA, L.A., LISBOA, G. \& CORADIN, L. 1990. Manual de manejo do herbário fanerogâmico. 2 ed. Centro de Pesquisas do Cacau, Ilhéus.

MÜLLER, S.C. \& WAECHTER, J.L. 2001. Estrutura sinusial dos componentes herbáceo e arbustivo de uma floresta costeira subtropical. Rev. Bras. Bot. 24(4):395-406.

MYERS, N., MITTERMEIER, R.A., MITTERMEIER, C.G., FONSECA, G.A.B. \& KENT, J. 2000. Biodiversity hotspots for conservation priorities. Nature. 403:853-858.

OLIVEIRA-FILHO, A.T. \& FONTES, M.A. 2000. Patterns of floristic differentiation among Atlantic Forests in Southeastern Brazil and the influence of climate. Biotropica. 32(4b):793-810.

OLIVEIRA-FILHO, A.T. 2009. Classificação das fitofisionomias da América do Sul cisandina tropical e subtropical: proposta de um novo sistema - prático e flexível - ou uma injeção a mais de caos? Rodriguésia. 60(2):237-258.

PABST, G.F.J. \& DUNGS, F. 1975. Orchidaceae Brasilienses. Kurt Schmersow, Hildesheim. (v. 1).

PEDRALLI, G., FREITAS, V.L.O., MEYER, S.T., TEIXEIRA, M.C.B. \& GONÇALVES, A.P.S. 1997. Levantamento florístico na estação ecológica do Tripuí, Ouro Preto, MG. Acta Bot. Bras. 11(2):191-213.

PERÓN, M.V. 1989. Listagem preliminar da flora fanerogâmica dos campos rupestres do Parque Estadual do Itacolomi - Ouro Preto/Mariana, MG. Rodriguésia. 67(1):63-69

PIFANO, D.S. 2007. Composição da flora fanerogâmica de três remanescentes de vegetação nativa da Zona da Mata de Minas Gerais. Dissertação de Mestrado, Universidade Federal de Lavras, Lavras.

PIFANO, D.S., VALENTE, A.S.M., CASTRO, R.M., PIVARI, M.O.D., SALIMENA, F.R.G. \& OLIVEIRA-FILHO, A.T. 2007. Similaridade entre os habitats da vegetação do Morro do Imperador, Juiz de Fora, Minas Gerais, com base na composição de sua flora fanerogâmica. Rodriguésia. 54(8):885-904.

PIRANI, J.R., MELLO-SILVA, R. \& GIULIETTI, A.M. 2003. Flora de Grão Mogol, Minas Gerais, Brasil. Bol. Bot. 21(1):1-24.

RODRIGUES, L.A., CARVALHO, D.A., OLIVEIRA-FILHO, A.T., BOTREL, R.T. \& SILVA, E.A. 2003. Florística e estrutura da comunidade arbórea de um fragmento florestal em Luminárias-MG. Acta Bot. Bras. 17(1):71-87.

ROGALSKI, J.M. \& ZANIN, E.M. 2003. Composição florística de epífitos vasculares no estreito de Augusto César, Floresta Estacional Decidual do Rio Uruguai, RS, Brasil. Rev. Bras. Bot. 26(4):551-556.

SILVA, N.R.S., MARTINS, S.V., MEIRA-NETO, J.A.A. \& SOUZA, A.L. 2004. Composição florística e estrutura de uma floresta estacional semidecidual montana em Viçosa, MG. Rev. Arvore 28(3):397-405.

SILVA, V.F., VENTURIN, N., OLIVEIRA-FILHO, A.T., MACEDO, R.L.G., CARVALHO, W.A.C. \& BERG, E. Van den. 2003. Caracterização 
estrutural de um fragmento de floresta semidecídua no município de Ibituruna, MG. Cerne. 9(1):95-110.

SMITH, A.R., PRYER, K.M., SCHUETTPELZ, E., KORALL, P., SCHNEIDER H. \& WOLF, P.G. 2006. A classification for extant ferns. Taxon. 55(3):705-731.

SYLVESTRE, L.S. 1997. Pteridófitas da reserva ecológica de Macaé de Cima. In Serra de Macaé de Cima: diversidade florística e conservação em Mata Atlântica (H.C. Lima \& R.R. Guedes-bruni, eds). Instituto de Pesquisas Jardim Botânico do Rio de Janeiro, Rio de Janeiro, p. 40-52.

TRYON, R.M. \& TRYON, A.F. 1982. Ferns and allied plants, with special reference to Tropical America. Springer-Verlag, New York.

VALENTE, A.S.M. 2007. Composição, estrutura e similaridade florística do estrato arbóreo de três fragmentos de floresta atlântica, na Serra Negra, município de Rio Preto, Minas Gerais, Brasil. Dissertação de Mestrado, Universidade Federal de Juiz de Fora, Juiz de Fora.
VALVERDE, O. 1958. Estudo regional da Zona da Mata de Minas Gerais. Rev. Bras. Geog. 20(1):1-82.

VELOSO, H.P., RANGEL, A.L.R. \& LIMA, J.C.A. 1991. Classificação da vegetação brasileira, adaptada a um sistema universal. Instituto Brasileiro de Geografia e Estatística, Rio de Janeiro.

VIANA, P.L. \& LOMBARDI, J.A. 2007. Florística e caracterização dos campos rupestres sobre canga na Serra da Calçada, Minas Gerais, Brasil. Rodriguésia. 58(1): 159-177.

WAECHTER, J.L. 1986. Epífitos vasculares da Mata Paludosa do Faxinal, Torres, Rio Grande do Sul Brasil. Ser. Bot. Iheringia. 34(1):39-49.

Recebido em 22/05/09

Versão reformulada recebida em 31/08/09

Publicado em: 07/09/09 